\title{
First results with 3-strap ICRF antennas in ASDEX Upgrade
}

\author{
V Bobkov ${ }^{1}$, F Braun ${ }^{1}$, R Dux ${ }^{1}$, A Herrmann ${ }^{1}$, H Faugel $^{1}$, \\ H Fünfgelder ${ }^{1}$, A Kallenbach ${ }^{1}$, R Neu ${ }^{1,2}$, J-M Noterdaeme ${ }^{1,3}$, \\ R Ochoukov ${ }^{1}$, Th Pütterich ${ }^{1}$, A Tuccilo ${ }^{4}$, O Tudisco ${ }^{4}$, Y Wang ${ }^{5}$, \\ Q Yang ${ }^{5}$ and ASDEX Upgrade team \\ ${ }^{1}$ Max-Planck-Institut für Plasmaphysik, EURATOM Association, Boltzmannstr. 2, \\ 85748 Garching, Germany \\ ${ }^{2}$ Fakultät für Maschinenwesen, Technische Universität München, Boltzmannstr. 15, \\ 85748 Garching, Germany \\ ${ }^{3}$ Department of Applied Physics, Gent University, 9000 Gent, Belgium \\ ${ }^{4}$ ENEA, Frascati, Italy \\ ${ }^{5}$ ASIPP, Institute of Plasma Physics, Chinese Academy of Sciences, Hefei, China
}

\begin{abstract}
The 3-strap antennas in ASDEX Upgrade allow ICRF operation with low tungsten $(\mathrm{W})$ content in the confined plasma with W-coated antenna limiters. With the 3-strap antenna configuration, the local $\mathrm{W}$ impurity source at the antenna is drastically reduced and the core $\mathrm{W}$ concentration is similar to the boron coated 2-strap antenna at a given ICRF power. Operation of the 3-strap antennas with the power ratio between the central and the outer straps of 1.5:1 and 2:1 is adopted to minimize the ICRF-specific $\mathrm{W}$ release.
\end{abstract}


a)

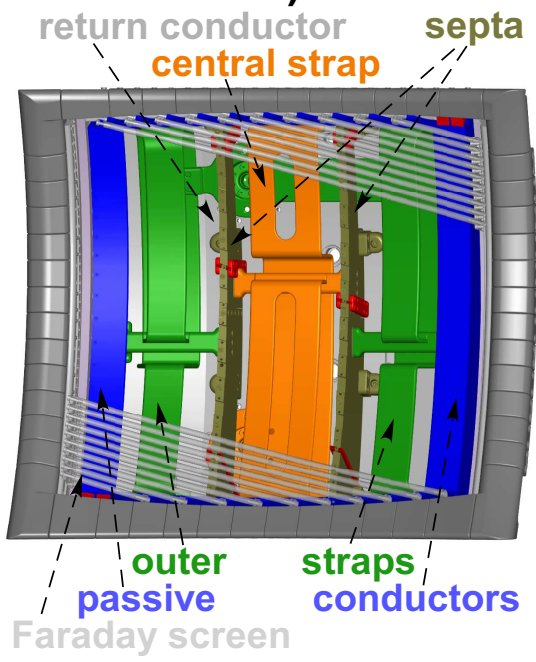

b)

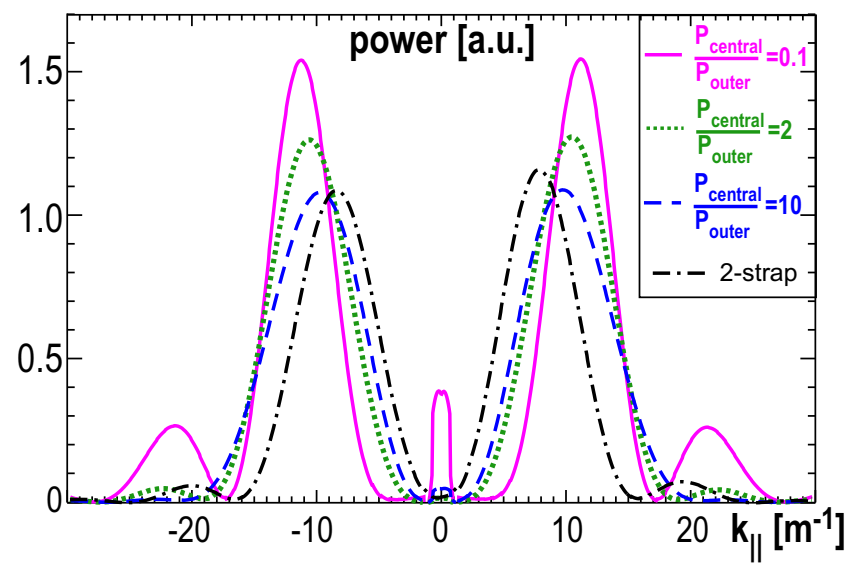

Figure 1. a) Drawing of the ASDEX Upgrade 3-strap ICRF antenna. The Faraday screen is only shown in the corners (in fact it is throughout the complete antenna face). b) Antenna $k_{\|}$spectra for the power ratio between the central strap and the outer straps of 0.1, 2:1 and 10:1.

After installation of the all-tungsten (W) wall in ASDEX Upgrade (AUG) [1], in particular the $\mathrm{W}$-coated antenna limiters which serve as the first limiters on the outer wall in AUG, ICRF (Ion Cyclotron Range of Frequencies)-specific W release became a serious problem. Two routes to improve the ICRF operation were pursued. The first route was to exchange the material of the antenna limiters by a low- $\mathrm{Z}$ alternative. In 2012, limiters of two of the four antennas were coated by boron (B) [2]. The W content in the confined plasma during operation of these B-coated antennas was decreased by at least a factor of 2 compared to that when operating the $\mathrm{W}$-coated antennas. The second route was to change the antenna design, working under the assumption that the RF sheaths driven by parallel RF electric fields are responsible for the ICRFenhanced $\mathrm{W}$ sputtering. The antenna was designed to reduce the RF image currents at protruding elements of the antenna frame which includes the antenna limiters [3]. Our design differs from previous attempts to reduce ICRF generated impurities in Tore Supra [4] and Alcator C-Mod [5]. For Tore Supra, the antenna design minimized the integrated parallel component of the $\mathrm{RF}$ electric field which failed to reduce $\mathrm{RF}$ impurities. At Alcator C-Mod, the antenna was aligned to the total magnetic field which effectively eliminated impurity source at the antenna. Prior to the 2015/2016 experimental campaign, the 2-strap ICRF antennas with the W-coated limiters were replaced by antennas with 3 straps. The 3 -strap antenna concept minimizes the RF image currents at the antenna frame. This is achieved by balancing the out-of-phase (dipole) contributions of the central strap and that of the outer straps. In this paper we report on the first experimental results achieved with the new 3-strap antennas.

The 3-strap antenna is shown in Fig. 1a. The outer straps are powered by a single 

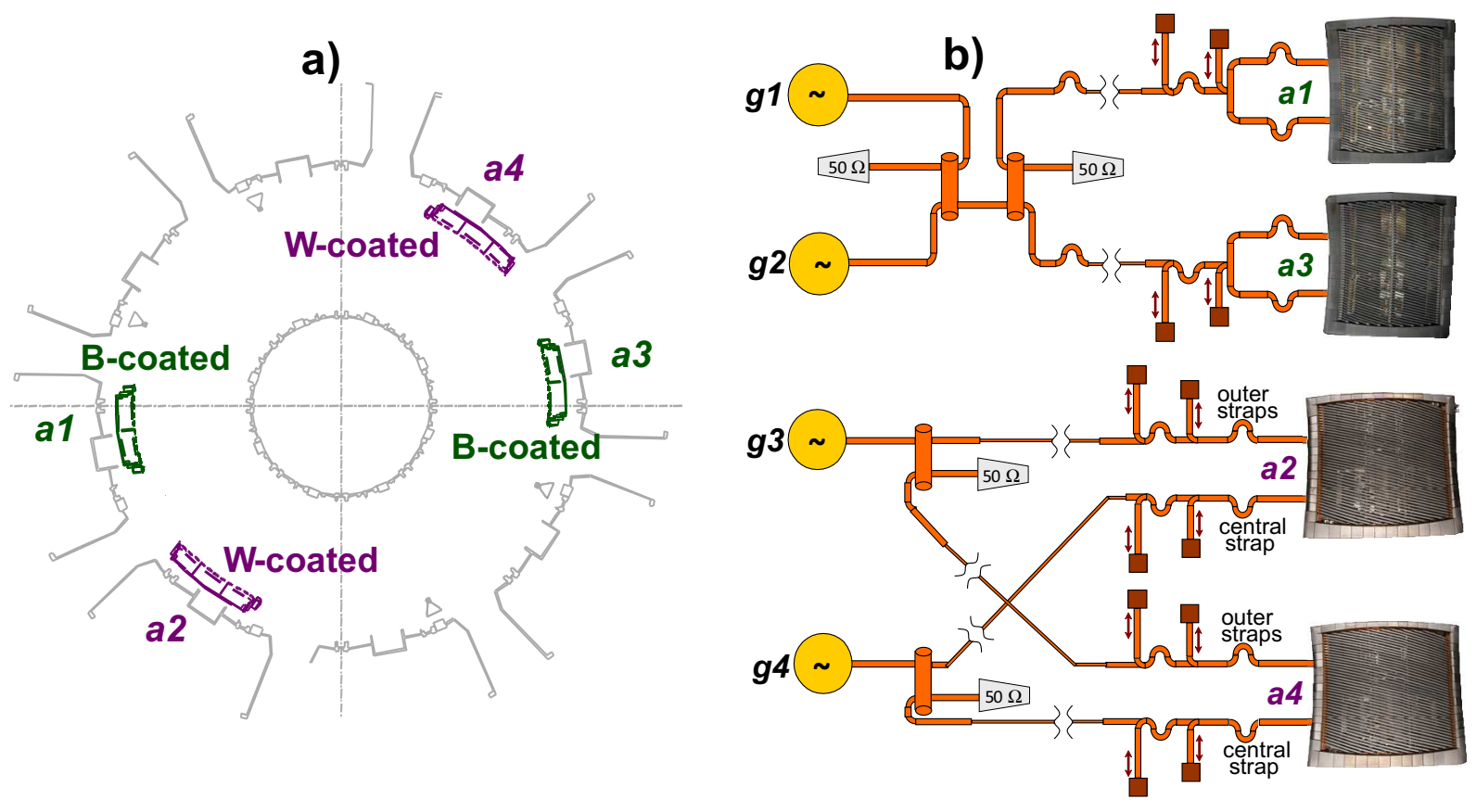

Figure 2. a) ASDEX Upgrade ICRF antenna toroidal arrangement for the 2015/2016 experimental campaign. b) RF generator connections of AUG ICRF antennas.

feeder. This is realized by connecting the outer straps to each other by a horizontal conjunction. The central strap has a separate feeder. The central and the outer straps are separated by septa electrically connected to the return conductor and to the Faraday screen. The non-resonant passive conductors are not powered directly, and are implemented to help reducing the RF image currents on the antenna limiters. The net power ratio between the central straps and the outer straps as well as the phasing between the straps can be changed. Fig. 1 b presents the parallel wave number $k_{\|}$power spectrum which is excited at the power ratio between the central strap and the outer straps of $0.1,2: 1$ and 10:1 in dipole phasing. The spectra are calculated using the electromagnetic code HFSS [6] with 3D antenna model and lossy dielectric loading. The spectra for the imbalanced configurations (power ratios of 0.1 and 10:1) have stronger similarities to the spectrum with the balanced dipole configuration (power ratio of 2:1) than to a spectrum of a classical monopole, primarily because of a significant effect of the residual power in the underpowered straps. For a reference the $k_{\| \mid}$spectrum for the 2-strap antenna is presented. If not mentioned otherwise in this paper, the power ratio close to 2:1 was chosen for the 3-strap antenna operation.

The toroidal arrangement of the ICRF antennas in AUG for the 2015/2016 experimental campaign is shown in Fig. 2(a). Four antennas, named $a 1$ to $a 4$, are used to couple the ICRF power to the plasma in AUG. The limiters of the 2-strap antennas $a 1$ and $a 3$ are B-coated, whereas the limiters of the 3-strap antennas $a 2$ and $a 4$ are W-coated. The four ICRF antennas are powered by four RF generators, named $g 1$ to g4. Antennas $a 1$ and $a 3$ are paired and connected to RF generators $g 1$ and $g 2$ with the 
a)

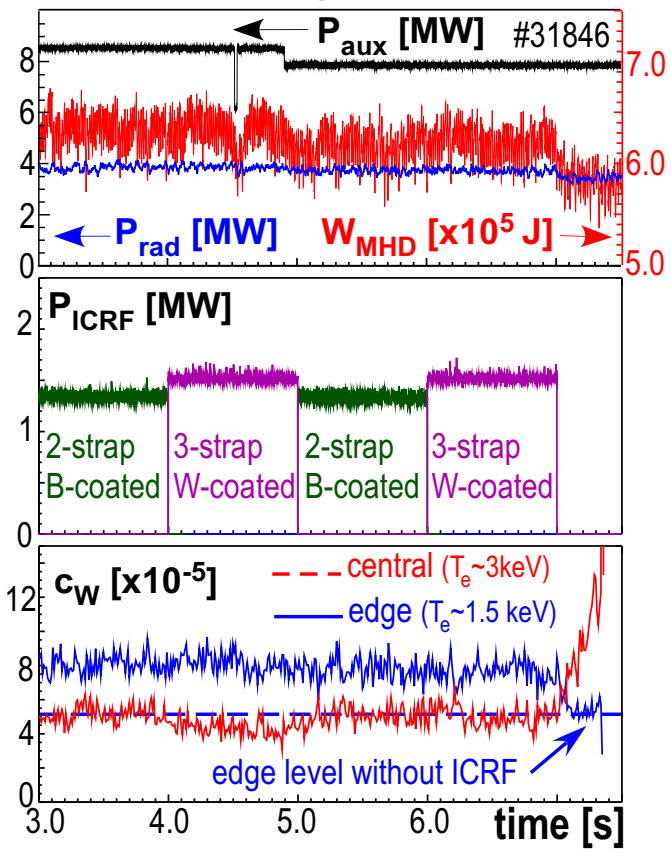

b)

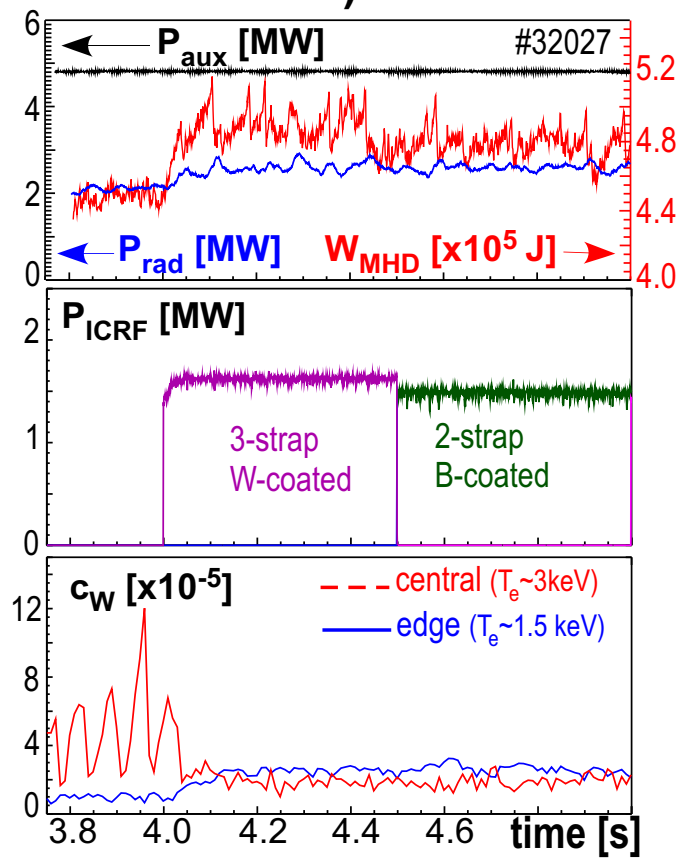

Figure 3. Comparison of the $W$ concentration in the H-mode plasma during operation of the B-coated 2-strap and the W-coated 3-strap antennas. a) $I_{p}=1 \mathrm{MA}$, deuterium gas injection rate of $1.1 \cdot 10^{22} \mathrm{el} / \mathrm{s}$ and $P_{\text {aux }}$ up to $8.7 \mathrm{MW}$, b) $I_{p}=1 \mathrm{MA}$, deuterium gas rate $2.8 \cdot 10^{22} \mathrm{el} / \mathrm{s}, P_{\text {aux }} \approx 4.8 \mathrm{MW}$.

$3 \mathrm{~dB}$ hybrid powering scheme with one feeder per antenna, as illustrated in Fig. 2(b). The central strap of $a 2$ and the central strap of $a 4$ are powered by RF generator $g 3$. The outer straps of $a 2$ and the outer straps of $a 4$ are powered by RF generator $g 4$. For the data used in this paper, only the dipole $(0-\pi)$ strap phasing is used for all the antennas (i.e between the central strap and the outer straps for a 3-strap antenna). The ICRF heating scheme is hydrogen minority in deuterium (combined with the second harmonic deuterium), with concentration of hydrogen between $1.5 \%$ and $6 \%$, toroidal magnetic field of 2.5 Tesla and frequency of $36.5 \mathrm{MHz}$.

The use of the W-coated 2-strap antennas led to significantly higher W content in the plasma, about a factor of 2 higher $\mathrm{W}$ concentration was found in comparison to the B-coated 2-strap antennas $[2,7]$. In Figure 3, the time traces of auxiliary power $P_{\text {aux }}$ (in addition to ICRF power $P_{I C R F}$ ), total radiated power $P_{\text {rad }}$ (dominated by main chamber radiation), stored plasma energy $W_{M H D}$ as well as the $\mathrm{W}$ concentration in the center around $T_{e} \approx 3 \mathrm{keV}$, and at the edge around $T_{e} \approx 1.5 \mathrm{keV}$ are shown. The ICRF power is toggled between the B-coated 2-strap antennas and the W-coated 3-strap antennas. The 3-strap antennas operation results in about the same core $\mathrm{W}$ content and $P_{\text {rad }}$ as that for the B-coated 2-strap antennas for a given ICRF power. As noted above, this means the new W-coated 3-strap antennas have substantially lower W content than the W-coated 2-strap antennas. At the same time, values of $W_{M H D}$ indicate that the 

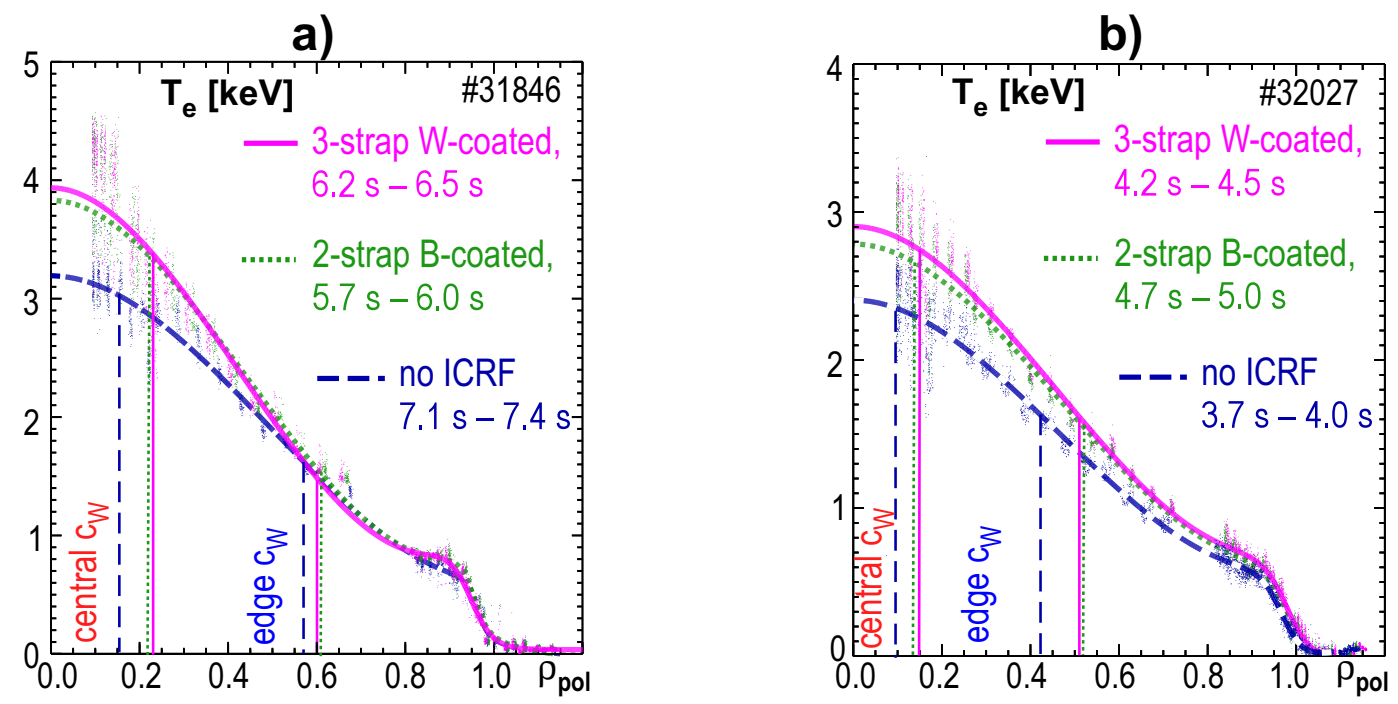

Figure 4. Comparison of $T_{e}$ profiles which correspond to different heating phases in Fig 3 with fits. Vertical lines indicate weighted radii at which $c_{W}$ is calculated.

heating effectiveness of the 3-strap antenna is not lower than that of the 2-strap antenna. The comparison between the 3-strap and B-coated 2-strap antennas are shown for two discharges: an up to $8.7 \mathrm{MW}$ auxiliary heated H-mode with the plasma current of $I_{p}=1 \mathrm{MA}$ in Fig. 3a and a $4.8 \mathrm{MW}$ auxiliary heated $\mathrm{H}$-mode with $I_{p}=1 \mathrm{MA}$ and higher gas injection in Fig. 3b.

Currently, the W-coated antennas are routinely used to avoid the $\mathrm{W}$ peaking, in a way similar to their use in the past when the antenna limiters were purely graphite. Examples of the $\mathrm{W}$ peaking can be seen in Fig. 3a after ICRF is turned off and in Fig. $3 \mathrm{~b}$ before the ICRF is turned on (spikes in the central $\mathrm{W}$ concentration correspond to sawteeth).

Figure 4 shows comparison of electron temperature $T_{e}$ profiles when the 2-strap or the 3-strap antennas are active as well as in the phases without $P_{I C R F}$ for both discharges from Fig. 3 correspondingly. Both antenna types lead to almost identical rise of $T_{e}$, apart from a small difference in the center due to a marginally higher $P_{I C R F}$ for the 3-strap antennas. The weighted radii where values of $c_{W}$ is measured are the same for the phase with 2-strap antenna and that with the 3-strap antenna. Thus we can reasonably assume that the core conditions stay the same when toggling between the two types of the antennas. When attributing the increase in $\mathrm{W}$ content during ICRF to the $\mathrm{W}$ source and not to modifications of the $\mathrm{W}$ transport in the scrape-off-layer (SOL) induced by ICRF (as suggested, e.g. in [8]), the observations of $c_{W}$ can be interpreted such that the total W source associated with the operation of the new 3-strap antenna is about equal to that of the 2-strap antennas. This means that the sum of the local and the remote $\mathrm{W}$ sources of the new 3-strap antenna is about equal to the remote $\mathrm{W}$ sources of the 2-strap antennas. We define "remote W sources" as the W sources not located at the limiters of active antennas. 
a)

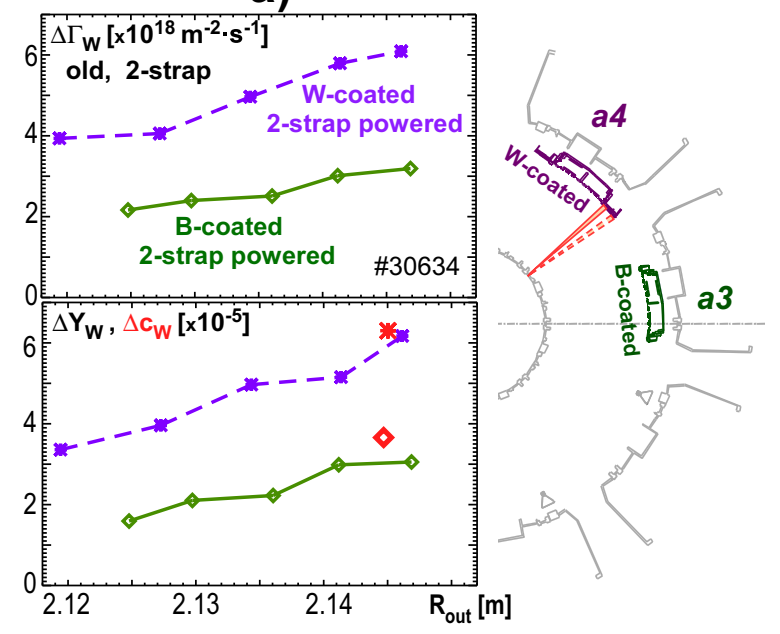

b)

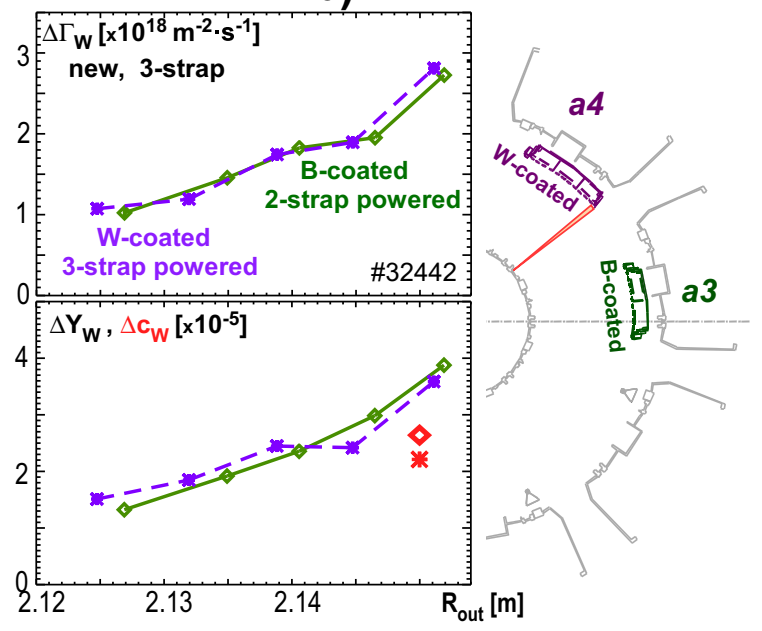

Figure 5. Comparison of the $W$ source at the right limiter (as seen from the plasma) of the $W$-coated antenna a4 when the $W$-coated antennas are operated (stars) with that from the same location when the B-coated antennas are operated (triangles). Large red symbols in the lower graph present $c_{W}$ around $T_{e} \approx 1.5 \mathrm{keV}$ measured when $R_{\text {out }} \approx 2.15$ $m$ (same symbol code). a) 2-strap antenna is $W$-coated (2014); b) 3-strap antenna is $W$-coated (2015).

Spectroscopic measurements suggest that the reduction of the $\mathrm{W}$ content with the 3 -strap antennas was achieved primarily by the reduction of the local ICRF-specific W source at the antenna limiters. Figure 5 compares the ICRF-specific $W$ influx $\Gamma_{W}$ and effective $\mathrm{W}$ sputtering yield $Y_{W}$ measured locally at the limiter of the old 2-strap broadlimiter antenna in 2014 in type-I ELMy H-mode discharge \#30634 (Fig. 5a) with that of the new 3-strap antenna in 2015 in discharge \#32442 (Fig. 5b), which is a repeat of discharge \#30634. The discharges had $I_{p}=0.8 \mathrm{MA}, P_{\text {aux }} \approx 5 \mathrm{MW}$ and deuterium gas rate of $1.2 \cdot 10^{22} \mathrm{el} / \mathrm{s}$. Values of $\Gamma_{W}$ and $Y_{W}$ during the operation of the B-coated antennas, which characterize the remote $\mathrm{W}$ source for this case, are taken as a reference. The corresponding lines of sight of the spectroscopic observations are shown separately for the old 2-strap broad-limiter antenna setup (two adjacent toroidal positions of views) and for the new 3-strap antenna setup (one toroidal row of views). The values of $\Gamma_{W}$ and $Y_{W}$ are averaged over $50 \mathrm{~ms}$ time intervals and over the lines of sight at the limiters in the same spatial poloidal range covering the AUG vertical coordinates between $z=-0.09 \mathrm{~m}$ and $z=0.42 \mathrm{~m}$ for both the new and the old setup. The values are plotted as a function of the outer plasma position $R_{\text {out }}$. It can be seen that at the right $a 4$ limiter (as seen from inside the plasma), the local $\mathrm{W}$-source for the 3-strap antenna equals approximately the remote $\mathrm{W}$ source for the B-coated 2-strap antennas. By large red symbols in the lower graph $c_{W}$ measured around $T_{e} \approx 1.5 \mathrm{keV}$ in the same discharges when $R_{\text {out }} \approx 2.15 \mathrm{~m}$ is shown. Thus one observes that relative reduction of the $\mathrm{W}$ source by about a factor of 2 since the installation of the new 3-strap antennas is consistent with the relative reduction of the $\mathrm{W}$ content observed in the confined plasma. 
a)

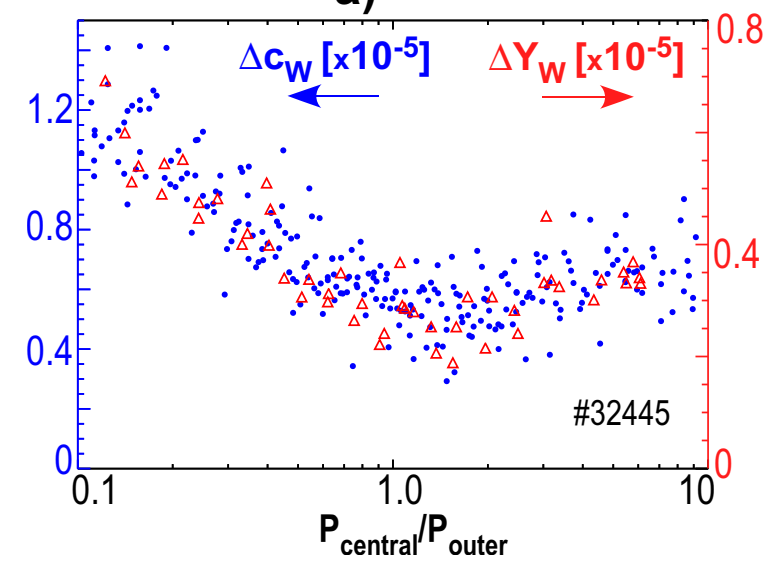

b)

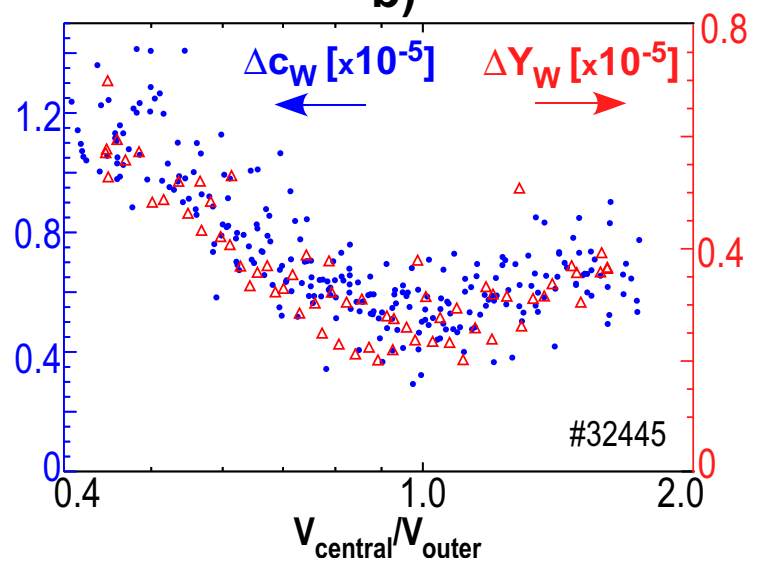

Figure 6. ICRF specific rise of the $W$ concentration (blue dots, values averaged over $20 \mathrm{~ms}$ ) and of the averaged effective $W$ sputtering yield measured on the right limiter of a 4 (read triangles, averaged over $40 \mathrm{~ms}$ ) during a strap power balance scan at fixed total ICRF power. Plotted as a function of (horizontal axis is logarithmic): a) ratio of ICRF power from the central strap to the power from the outer straps; b) ratio between the voltages at the feeders of the central strap and the outer straps.

One has to note that for the comparison above between the old (Fig. 5a) and the new (Fig. 5b) discharges, the data is available only within the limited spatial coverage of the $\mathrm{W}$ source diagnostics with a half of the right antenna limiter covered. Thus possible changes and asymmetries of the full spatial distribution of the local and remote W sources cannot be described.

For the ICRF-specific W release the effect of the power balance between the antenna straps is important. In Figure 6a the ICRF-specific rise of the W concentration $\Delta c_{W}$ around $T_{e} \approx 1.5 \mathrm{keV}$ and that of the effective sputtering yield $\Delta Y_{W}$ averaged over lines of sight on the right limiter of $a 4$ are shown as a function of the power ratio between the central strap and the outer straps $P_{\text {central }} / P_{\text {outer }}$, in H-mode discharge \#32445 with $I_{p}=0.8 \mathrm{MA}, P_{\text {aux }}=5 \mathrm{MW}$ and constant $P_{I C R F}=1 \mathrm{MW}$, using the saddle coils [9] to mitigate type-I ELM activity at high edge plasma density. The coils are known to increase the SOL density [10] and were kept at fixed configuration and fixed currents to provide constant and the calm edge conditions with reduced ELM activity when the power ratio was scanned. Although the high edge density scenario usually implies the smallest sensitivity of the $\mathrm{W}$ release to $\mathrm{RF}$ parameter variation, it is observed then the $\mathrm{W}$ source and the $\mathrm{W}$ content decrease when $P_{\text {central }} / P_{\text {outer }}$ increases until the lowest values are registered between $P_{\text {central }} / P_{\text {outer }}=1.0$ and $P_{\text {central }} / P_{\text {outer }}=3.0$. Interestingly, the response of the $\mathrm{W}$ levels to the variation of $P_{\text {central }} / P_{\text {outer }}$ at high $P_{\text {central }} / P_{\text {outer }}$ is weaker compared to that at low $P_{\text {central }} / P_{\text {outer }}$. This can be interpreted as the effect of the specific RF feeding properties of the antenna, in particular as the effect of the $\mathrm{RF}$ cross-coupling between the straps. In Figure $6 \mathrm{~b} \Delta c_{W}$ and $\Delta Y_{W}$ are plotted as a function of the ratio of the voltages in the feeders of the central strap and the outer 
straps $V_{\text {central }} / V_{\text {outer }}$. The voltage is measured in the resonant line of each feeder at the voltage maximum. When the power from the central strap is high, the currents in the outer straps induced by the RF cross-coupling do not allow the voltage balance of the antenna to be de-tuned significantly. Thus the voltage ratio does not reach high values.

It is challenging to disentangle whether the change of the $\mathrm{W}$ content during the scan of the power ratio of the 3-strap antenna is due to local effects of the image currents at the antenna frame or due to the changes of RF power absorption and coupling. As can be seen in Fig. $1 \mathrm{~b}$, the antenna $k_{\|}$power spectrum can change significantly when the power ratio is varied. Largest change is for the ratio of $1: 10$, especially close to $k_{\|} \approx 0$ for which the power is poorly absorbed and for high $\left|k_{\|}\right|$for which the power is poorly coupled. This can influence the plasma-antenna interactions. Nevertheless, the $\Delta c_{W}$ and $\Delta Y_{W}$ dependencies on strap power balance are very similar. This indicates that the local antenna RF currents mostly influence the $\mathrm{W}$ sources and the $\mathrm{W}$ content. A more comprehensive analysis of the local measurements during the scan of the power balance of the antenna and a comparison to electro-magnetic calculations will be published separately.

For standard operation of the 3-strap antennas, a feedback-controlled power ratio with values of $1.5: 1$ or of $2: 1$ is usually adopted. Considering Fig. 2, this has the drawback of uneven power distribution between $g 3$ and $g 4$ and reduced total power. Going to the ratio of 1:1 is an option for high-density scenarios. However it also has a drawback that the maximum voltages in the resonant lines become higher for the feeder powering the outer straps.

The first experimental results using the new 3-strap antennas in ASDEX Upgrade in the dipole strap phasing show a significant reduction of the $\mathrm{W}$ source and the $\mathrm{W}$ content as compared to the 2-strap antennas used previously. The new antennas with the W-coated limiters can now be used in the same AUG operational space as the 2strap antennas with the B-coated limiters. The lowest values of the ICRF-specific W release were measured in the range of power ratio between the central strap and the outer straps from 1:1 to $3: 1$. Further analysis of a more complete assessment of the 3-strap antenna will be presented elsewhere.

\section{References}

[1] Neu R. et al., Plasma Phys. Control. Fusion 49 (2007) B59-B70

[2] Bobkov V. et al., Nucl. Fusion 53 (2013) 093018.

[3] Bobkov V. et al., Nucl. Fusion 50 (2010) 035004.

[4] Colas L., J. Nucl. Mater. 438 (2013) S330-S333.

[5] Wukitch S. et al., Phys. Plasmas 20 (2013) 056117.

[6] High Frequency Structure Simulator, www.ansys.com.

[7] Czarnecka A., J. Nucl. Mater. 463 (2015) 601-604.

[8] Terry A., 2012 Proc. 24th Int. Conf. on Fusion Energy (San Diego, 2012), EX/P5-39, http://wwwnaweb.iaea.org/napc/physics/FEC/FEC2012/index.htm

[9] Suttrop W. et al., Phys. Rev. Lett. 10622 (2011) 225004.

[10] Bobkov V. et al., AIP Conf. Proc. 1580 (2014) 271. 